\title{
Preparation of Charcoal Pellets from Eucalyptus Wood with Different Binders
}

\author{
Alejandro Amaya, Mariana Corengia, Andrés Cuña, Jorge De Vivo, Andrés Sarachik, \\ Nestor Tancredi*
}

DETEMA, Facultad de Química, Universidad de la República, Montevideo, Uruguay

Email address:

nestor@fq.edu.uy (N. Tancredi)

\section{To cite this article:}

Alejandro Amaya, Mariana Corengia, Andrés Cuña, Jorge De Vivo, Andrés Sarachik, Nestor Tancredi. Preparation of Charcoal Pellets from Eucalyptus Wood with Different Binders. Journal of Energy and Natural Resources. Vol. 4, No. 2, 2015, pp. 34-39.

doi: $10.11648 /$ j.jenr.20150402.12

\begin{abstract}
At present, there is great interest in using biomass as an alternative energetic source, as it is renewable and environmentally friendly. In the case of solid fuels, biomass has low energetic density, although it can be increased by charring and pelletizing. These methods also allow the improvement of physical properties, such as hydrophobicity and resistance to microbiological attack. In this work, the agglomeration of charcoal dust produced from sawmill waste with three different binders (wood tar, molasses and starch) was studied. The procedure included agglomeration and curing by heating in air atmosphere. The prepared charcoal pellets showed appropriate mechanical resistance, higher heating value than the original wood residues and higher energetic density than charcoal. Molasses and tar used as binders in the preparation of fuel pellets allow energy densification and an adequate durability of the products.
\end{abstract}

Keywords: Charcoal, Pellet, Binders, Eucalyptus Wood, Renewable Energy

\section{Introduction}

In the last decades high interest has been raised worldwide in using biomass materials as an alternative to fossil fuels [1-4]. The main advantages of this substitution are that biomass is a renewable and environmental friendly energetic source since it leads to lower emissions of greenhouse and acid gases.

Some problems associated to biomass materials in their original form are high moisture content, irregular shape and sizes and low bulk and energetic densities [5]. These factors increase storage, handling and transportation costs. Moreover, biomass is subject to microbiological attack during storage [6, 7] and may cause plague infestation [8].

Carbonization is a way to increase energetic density as char heating value is about 25-30 MJ kg-1 compared to $15 \mathrm{MJ} \mathrm{kg}-1$ for raw biomass [9-11]. Also, carbonization increases hydrophobicity, resulting in a decrease of moisture content and microbiological growing [12]. Nevertheless carbonization products are highly friable and lead to the generation of carbon dust, a difficult product to handle and that may cause explosions [13]. These problems may be overcome by milling the charcoal and pelletizing carbon dust by means of adequate binders. Pelletization would contribute not only to the durability of the product but also to an increase of its energetic density. In addition, carbon pellets have the same advantages as charcoal compared to the direct use of biomass as fuel (such as higher heating value and lower moisture content) [14-18].

Different binders have been used in order to achieve particle agglomeration and good cohesion properties [19-20]. In some cases, binding has been explained as due to adherence between surfaces enhanced by bonds with the binder [21].

At present, forest biomass in Uruguay, as in other developing countries [22-24], appears as an important source of renewable energy [25]. In addition to this, due to the activity of sawmills, huge quantities of residues are produced and accumulated as sawdust or other irregular-shaped pieces of wood. These residues could be used as a raw material in the production of energy [26].

In this work, the agglomeration of charcoal produced from sawmill waste with three different binders (wood tar, molasses and starch) was studied. The procedure included agglomeration and curing by heating in air atmosphere. Physico-chemical properties of raw material and charcoal 
pellets were determined.

\section{Materials and Methods}

\subsection{Raw Materials}

Sawmill residues (Eucalyptus grandis wood, pre-dried), with prismatic shapes, about $2 \mathrm{~cm}$ thickness, $5 \mathrm{~cm}$ width, $10-30 \mathrm{~cm}$ length, were carbonized in a pyrolysis kiln in a previous experiment [27], obtaining charcoal pieces of similar shape and size (yield $28.3 \%$, dry basis) and wood tar as a by-product. Charcoal was grinded in a mortar, sieved and 30-50 mesh size fractions were selected. Sugar cane molasses were obtained from ANCAP, the national company dedicated to oil refinery and ethanol production. Aqueous starch solutions were prepared from potato starch.

\subsection{Pellet Preparation}

Pellets were prepared by mixing grinded charcoal with the binder, pressing the mixture in a manual Parr press, at $15 \mathrm{MPa}$ during $1 \mathrm{~min}$ and cured as indicated below. When tar was used as a binder, a mass ratio tar/charcoal of 1.1 was used to prepare the mixture. Then cylindrical pellets of mass $0.55-0.65 \mathrm{~g}$, diameter $1.1 \mathrm{~cm}$ and height $0.7 \mathrm{~cm}$ were made by cold compression. They were cured in an oven at $105^{\circ} \mathrm{C}$ during 24 $\mathrm{h}$, in order to obtain uniform pellets with adequate durability. After curing, pellets were stored in a desiccator and then mechanical resistance tests were performed. Other charcoal/tar ratios were tested, but those pellets showed very low mechanical resistance.

When molasses was used as a binder, the best molasses/charcoal weight ratio for achieving a good agglomeration was 1.3; cylindrical pellets of mass $0.5 \mathrm{~g}$, diameter $1.1 \mathrm{~cm}$ and height $0.7 \mathrm{~cm}$ were prepared. Curing was carried out in an oven at $162-179^{\circ} \mathrm{C}$ for $24 \mathrm{~h}$. This temperature range was chosen from TG data in order to avoid molasses combustion and allow caramelization.

When starch was used as a binder, a mixture of $85 \mathrm{~cm} 3$ of water and $3 \mathrm{~g}$ of starch was heated up to the boiling point; at this time $50 \mathrm{~g}$ of $30-50$ mesh preheated charcoal were added while stirring slowly. The obtained mixture was cooled, shaped into cylindrical pellets as described above and cured at $105{ }^{\circ} \mathrm{C}$ for $24 \mathrm{~h}$. Other preparation procedures, including the change of water/starch/charcoal ratio or the use of cold water were discarded as the obtained pellets had inadequate mechanical strength.

\subsection{Analysis of Raw Materials and Products}

For raw materials and products proximate analysis, elemental analysis, determination of heating value, apparent and bulk density and TGA were carried out. For pellets mechanical properties were also tested.

Proximate analysis included: moisture determination (ASTM D 2867-70 for wood, charcoal and starch), ashes determination (ASTM 2866-70) and volatile matter determination (ISO 5621-1981). As molasses has a high volatile content and caramelization occurs at about 118-129 ${ }^{\circ} \mathrm{C}$ [28], its moisture content was estimated from TGA in air. For wood tar, also with a high volatile content, moisture content was determined by distillation with toluene.

Elemental analysis was carried out in a Carlo Erba model EA 1108 CHNS - OR equipment. For the determinations of heating value a Parr 1341 Plain Oxygen Bomb Calorimeter was used. Apparent densities were determined by mercury immersion. Bulk densities were determined by pouring the material into a graduated container and measuring its mass. Thermogravimetric analyses were carried out in a Shimadzu TG-50 equipment, in air atmosphere $\left(50 \mathrm{~cm}^{3} \mathrm{~min}^{-1} \mathrm{STP}\right.$, dried by carbon molecular sieves), at a heating rate of $2{ }^{\circ} \mathrm{C} \min ^{-1}$ up to $850{ }^{\circ} \mathrm{C}$. Pellets mechanical properties (Impact Resistance Index, IRI, and friability) were tested by dropping the pellets from $1 \mathrm{~m}$ (IRI) and by rolling $6 \mathrm{~g}$ of pellets for $4 \mathrm{~min}$ at $25 \mathrm{rpm}$ (friability, Erweka equipment) [19, 29]. SEM images of selected samples were obtained with a JEOL JSM $5900 \mathrm{~L}$ Scanning Electron Microscope (High Technology Service, School of Sciences).

\section{Results and Discussion}

\subsection{Raw Materials}

In Tables 1 and 2 raw materials and products characterization are shown.

Differences among wood residue and charcoal values can be explained by the devolatilization during carbonization, which produces an increase in ashes content, fixed carbon and carbon content, as well as a decrease in oxygen content as a consequence of $\mathrm{CO}$ and $\mathrm{CO}_{2}$ formation. Molasses and starch showed low fixed carbon content as expected. For charcoal and charcoal dust, their heating values are the highest for all the samples and their apparent and bulk densities are the lowest. The low value of charcoal bulk density is the justification for a densification attempt.

Fig. 1 and 2 show the TG and DTG of the different raw materials in air atmosphere. In air, wood residues combustion shows a maximum rate at $300{ }^{\circ} \mathrm{C}$; the autoignition temperature is $250{ }^{\circ} \mathrm{C}$, in accordance with reported values in literature [30].

Autoignition temperatures of about $300{ }^{\circ} \mathrm{C}, 270{ }^{\circ} \mathrm{C}$ and $380{ }^{\circ} \mathrm{C}$ are found for wood tar, starch and charcoal, respectively. For all the graphs but that of charcoal two main peaks are shown: one at low temperatures, corresponding to volatile ignition, and a second one close to $500{ }^{\circ} \mathrm{C}$, corresponding to char combustion. In the case of molasses a peak beginning at $120^{\circ} \mathrm{C}$ with maximum at $140{ }^{\circ} \mathrm{C}$ appears; it is attributable to molasses caramelization [28]. At $177{ }^{\circ} \mathrm{C}$ volatile matter combustion begins, reaching a maximum at $200{ }^{\circ} \mathrm{C}$. At $440{ }^{\circ} \mathrm{C}$ char combustion starts. 
Table 1. Proximate and Elemental analysis of raw materials (\%, dry basis).

\begin{tabular}{|c|c|c|c|c|c|c|c|c|}
\hline \multirow{2}{*}{ Sample } & \multicolumn{4}{|c|}{ Proximate Analysis } & \multicolumn{4}{|c|}{ Elemental Analysis (ash free) } \\
\hline & Moisture & Ash & Volatile Matter & Fixed Carbon & $\mathbf{C}$ & $\mathbf{H}$ & $\mathbf{N}$ & $\mathbf{O}^{\mathrm{a}}$ \\
\hline Wood residue & 9.4 & 0.2 & 87.8 & 12.0 & 48.5 & 5.9 & $<0.1$ & 45.6 \\
\hline Charcoal & 6.1 & 1.1 & 19.3 & 79.6 & 77.2 & 2.5 & $<0.1$ & 20.3 \\
\hline Wood tar & 12.6 & 4.1 & 67.9 & 28.0 & 40.0 & 6.3 & $<0.1$ & 53.7 \\
\hline Molasses & 19.0 & 5.6 & 88.4 & 6.1 & 42.7 & 3.8 & 0.9 & 52.6 \\
\hline Starch & 12.0 & 0.3 & 98.2 & 1.5 & 46.9 & 5.6 & 0.3 & 47.2 \\
\hline Tar pellet & 9.5 & 2.8 & 46.1 & 51.1 & 74.4 & 3.7 & 0.3 & 21.6 \\
\hline Starch pellet & 3.0 & 1.3 & 25.1 & 73.6 & 80.1 & 2.9 & $<0.1$ & 17.0 \\
\hline
\end{tabular}

${ }^{a}$ by difference

\subsection{Pellets}

Pellets properties are shown in Tables 1 and 2. All the pellet properties are close to that of charcoal, as the curing process affects mainly the binder. This is especially remarkable for starch pellet, as charcoal is largely the major component. The only difference is observed in bulk density, larger for pellets, as expected. Regarding to mechanical resistance, all the pellets passed the IRI test and the losses after friability test were lower than $3 \%$ in all cases. These results are considered acceptable.

The SEM of the pellets and the charcoal are shown in Fig. 3. The completely separated charcoals particles are shown in Fig. 3a. The binding properties of starch are observed in Fig. 3b, as white connections between the charcoal particles. The union of different particles is also clearly observed for the tar pellet in Fig. 3c and for the molasses pellet in Fig. 3d.

In Fig. 4 and 5 TG and DTG in air for the prepared pellets and charcoal are compared. The main charcoal combustion peak is also seen for the pellets agglomerated with tar and starch, but for the pellets agglomerated with molasses the peak shifts to lower values. For molasses and tar pellets the curing and pelletization process cause the lowering of their autoignition temperatures compared to charcoal, though none of them were lower than $250{ }^{\circ} \mathrm{C}$. This is due to the high volatile content of the binders. TG and DTG for starch pellets are very close to that of charcoal: in this case the binder content is very low and curing is almost a drying process.

Table 2. Heating values (dry basis) and apparent and bulk densities of raw materials (P: pellets).

\begin{tabular}{lllll}
\hline Sample & High heating value $\left(\mathbf{M J ~ k g}^{-1}\right)$ & Low heating value $\left(\mathbf{M J ~ k g}^{-1}\right)$ & Apparent density $\left(\mathbf{g ~ c m}^{-3}\right)$ & Bulk density $\left(\mathbf{g ~ c m}^{-3}\right)$ \\
\hline Wood residue & 18.9 & 17.6 & 0.72 & $0.21-0.28$ \\
Sawdust & 18.9 & 17.6 & - & 0.28 \\
Charcoal & 29.6 & 29.2 & 0.33 & 0.12 \\
Charcoal dust & 29.6 & 29.2 & - & 0.22 \\
Wood tar & 21.6 & 20.4 & 1.17 & 0.31 \\
Molasses & 15.0 & 11.7 & 1.48 & 0.30 \\
Starch & 17.1 & 16.1 & 0.55 & 0.19 \\
Tar P. & 30.1 & 29.5 & 0.58 & 0.31 \\
Molasses P. & 25.4 & 24.8 & 0.56 & 0.30 \\
Starch P. & 30.8 & 30.2 & 0.36 & 0.19 \\
\hline
\end{tabular}

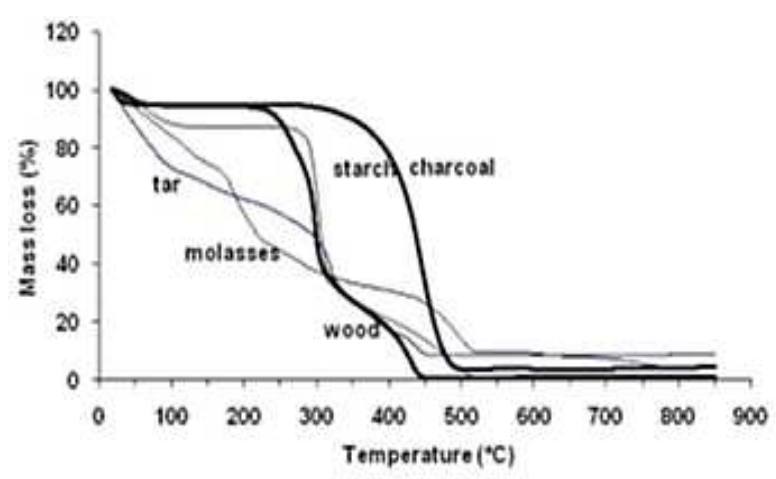

Figure 1. TG curves for raw materials in air atmosphere.

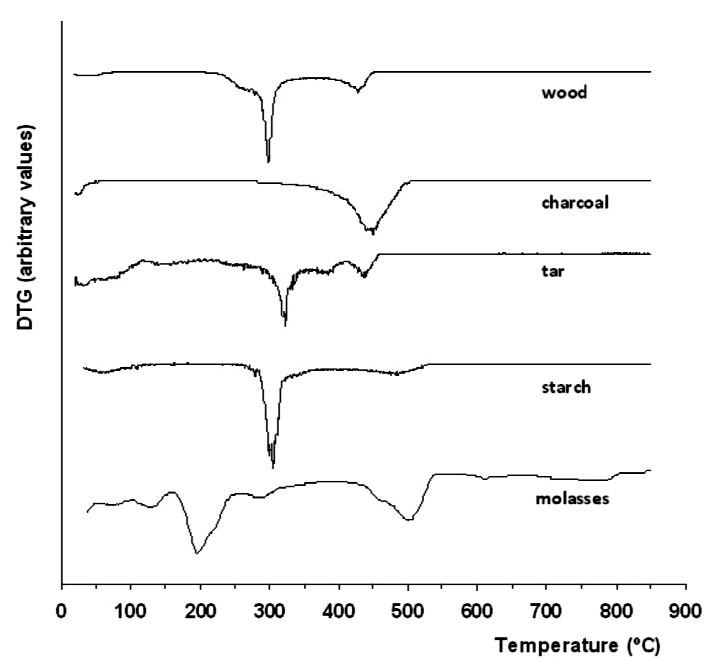

Figure 2. DTG curves for raw materials in air atmosphere. 


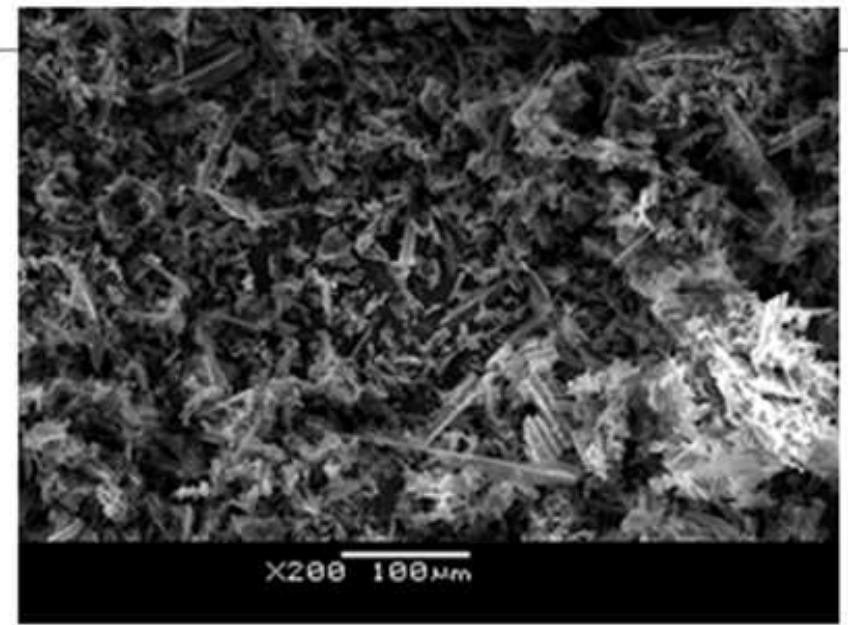

a) charcoal

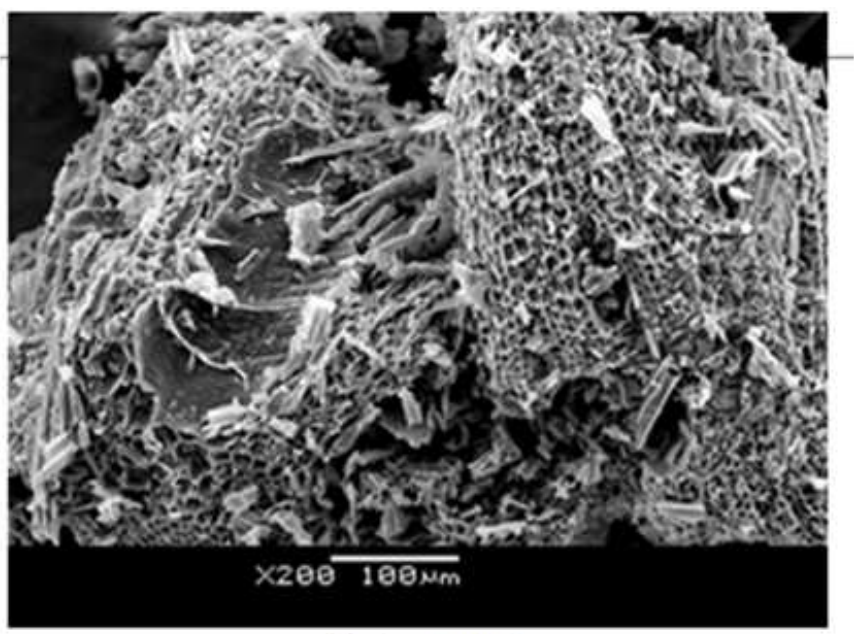

b) starch pellet

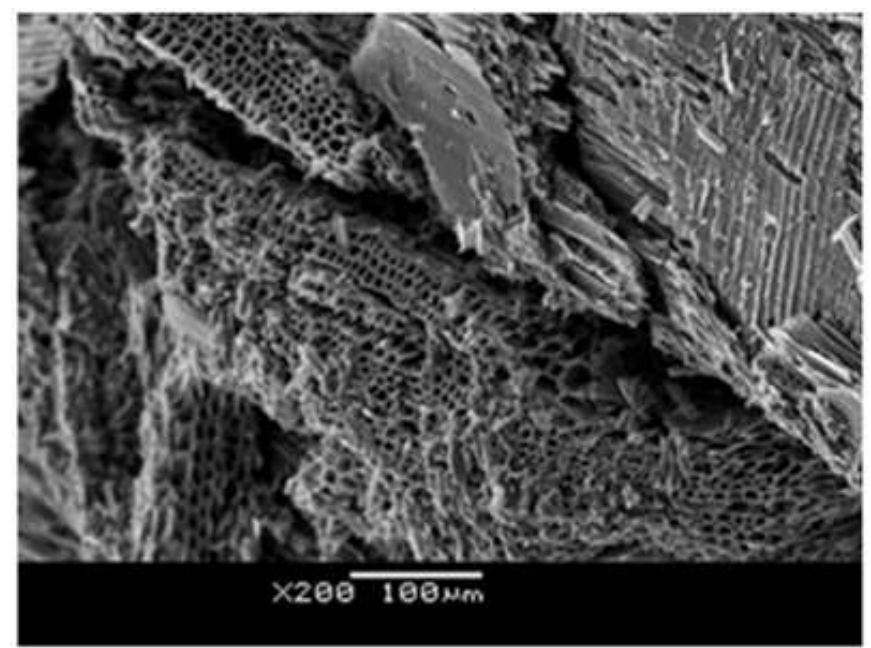

c) tar pellet

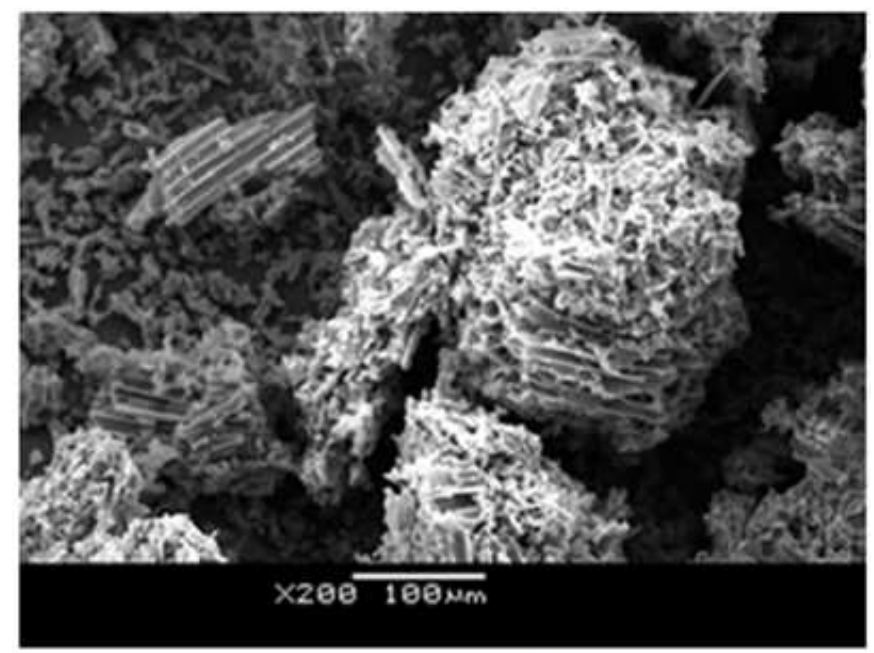

d) molasses pellet

Figure 3. SEM images.

\subsection{Energetic Densities}

As fuels are usually transported by volume, energetic density expressed as energy by volume is a better indicator of the fuel energy content than heating value.

An attempt to compare energetic densities of raw materials and products was made by defining the Energetic Density (ED) as:

$\mathrm{ED}=$ Low heating value (w.b.) $\mathrm{x}$ apparent density (1)

The calculated EDs are shown in Table 3. For pellets, EDs are higher than that for charcoal, and in the case of tar pellets ED is higher than that for wood also. These results indicate that pelletization worked as an energy densification method. Despite that ED is a property independent of pellet shape (useful for comparison among different fuels), for transportation purposes the space between the pieces of each material should be taken into account. Then, a new parameter, Packed Energetic Density (PED) was defined:

PED $=$ Low heating value (w.b.) $\mathrm{x}$ bulk density(2)

Calculated values for PED are shown in Table 5, including the values for sawdust and charcoal dust. Wood and charcoal as dust show higher PED values than the materials in pieces, because of the lower void volumes.

PED increases in the order charcoal $<$ wood $<$ wood sawdust $<$ charcoal dust $<$ pellets with the exception of starch pellets, with a PED lower than charcoal dust. In order to evaluate these results, the difficulties for dust transport and storage and health risks involved in its handling should be considered. With the exception of starch pellets, energetic densification was achieved by the pelletization method described in this work. 


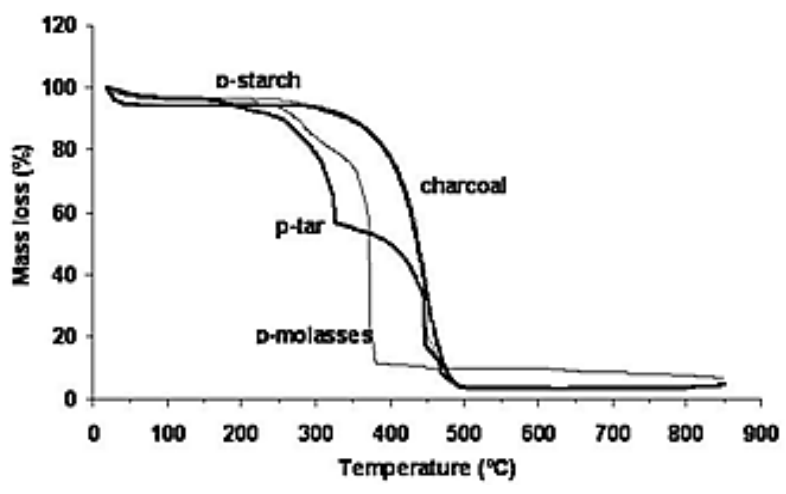

Figure 4. TG in air atmosphere of pellets and charcoal.

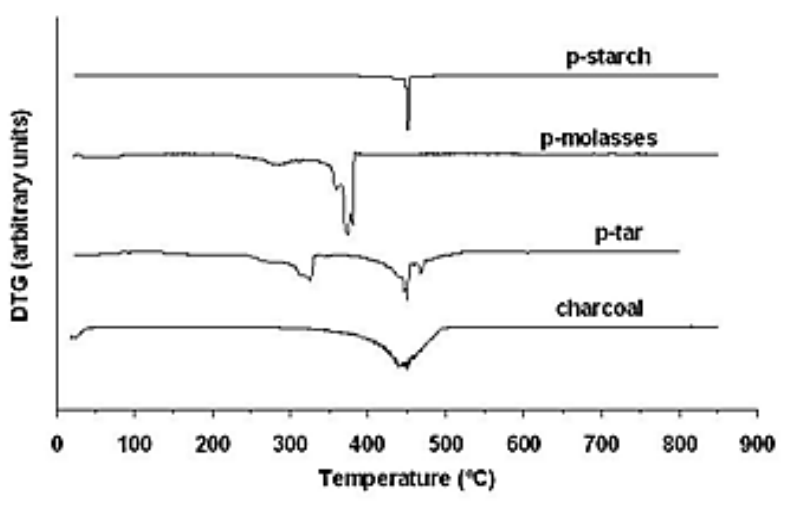

Figure 5. DTG in air atmosphere of pellets and charcoal.

Table 3. Energetic densities.

\begin{tabular}{lll}
\hline Sample & $\begin{array}{l}\text { Energetic Density } \\
\text { ED }\left(\mathbf{G J ~ m}^{-3}\right)\end{array}$ & $\begin{array}{l}\text { Packed Energetic Density } \\
\text { PED }\left(\mathbf{G J ~ m}^{-3}\right)\end{array}$ \\
\hline Wood Residue & 13.6 & $3.7-5.3$ \\
Sawdust & - & 5.3 \\
Charcoal & 9.6 & 3.5 \\
Charcoal Dust & - & 6.4 \\
Tar Pellet & 17.1 & 9.1 \\
Molasses Pellet & 13.9 & 7.4 \\
Starch Pellet & 10.9 & 5.7 \\
\hline
\end{tabular}

\section{Conclusions}

Charcoal pellets prepared from charcoal dust and three different binders showed appropriate mechanical resistance. They also exhibited higher heating value than the original wood residues and higher energetic density than charcoal. For molasses and tar pellets, packed energetic densities were higher than those for wood and charcoal, either as pieces or dust. Molasses and tar used as binders in the preparation of fuel pellets allow energy densification and an adequate durability of the products.

\section{Acknowledgements}

This work was financed by Project PDT 47/08, DINACYT, Ministerio de Educación y Cultura, Uruguay. Elemental analysis was performed at "Departamento Estrella Campos", Facultad de Química, Universidad de la República, Uruguay.

\section{References}

[1] I. Hannula. "Co-production of synthetic fuels and district heat from biomass residues, carbon dioxide and electricity: Performance and cost analysis. Biomass and Bioenerg., vol. 74, pp. 26-46, March 2015.

[2] J. Bisquert. "Materials for production and storage of renewable energy". J. Phys. Chem. Lett., vol 2, pp. 270-271, February 2011.

[3] P. Moriarty and D. Honnery. "The transition to renewable energy: make haste slowly”. Environ. Sci. Technol., vol. 45, pp. 2527-2528, March 2011.

[4] N. Kaliyan and V. Morey. "Factors affecting strength and durability of densified biomass products". Biomass Bioenerg., vol. 33, pp. 337-359, March 2009.

[5] Z. Miao, T. Grift, A. Hansen, and K. C. Ting. "Energy requirement for lignocellulosic feedstock densifications in relation to particle physical properties, preheating, and binding agents". Energ. Fuel vol. 27, pp. 588-595, January 2013.

[6] R. Wakeling and P. Morris. "Wood deterioration: Ground contact hazards". ACS Sym. Ser., vol. 1158, pp. 131-146, June 2014.

[7] M. Barontini, S. Crognale, A. Scarfone, P. Gallo, F. Gallucci, M.Petruccioli, L. Pesciaroli and L. Pari "Airborne fungi in biofuel wood chip storage sites”. Int. Biodeter. Biodegr., vol. 90, pp. 17-22, May 2014.

[8] M. Overbeck and M. Schmidt. "Modelling infestation risk of Norway spruce by Ips typographus (L.) in the Lower Saxon Harz Mountains (Germany)". Forest Ecol. Manag., vol. 266, pp. 115-125, February 2012.

[9] I. Niedziółka, M. Szpryngiel, M. Kachel-Jakubowska, A. Kraszkiewicz, K. Zawiślak, P. Sobczak and R. Nadulski. "Assessment of the energetic and mechanical properties of pellets produced from agricultural biomass" Renew. Energ., vol. 76, pp. 312-317, April 2015.

[10] V. Bustamante-García, A. Carrillo-Parra, H. González-Rodríguez, R. Ramírez-Lozano, J. J. Corral-Rivas, and F. Garza-Ocañas. "Evaluation of a charcoal production process from forest residues of Quercus sideroxyla and Humb., \& Bonpl. in a Brazilian beehive kiln”. Ind. Crop Prod., vol. 42, pp. 169-174, March 2013.

[11] M. Horio, A. Suri, J. Asahara, S. Sagawa and C. Aida. "Development of biomass charcoal combustion heater for household utilization". Ind. Eng. Chem. Res., vol. 48, pp. 361-372, January 2009.

[12] D. Medic, M. Darr, A. Shah and S. Rahn. "Effect of torrefaction on water vapor adsorption properties and resistance to microbial degradation of corn stover". Energ. Fuel, vol. 26, pp. 2386-2393, April 2012.

[13] R. K. Eckhoff, Dust Explosions in the Process Industries, 3rd ed. Boston: Gulf Professional Publishing/Elsevier, 2003, pp. 256-263.

[14] H. Li, L. Jiang, C. Li, J. Liang, X. Yuan, Z. Xiao, Z. Xiao and H. Wang "Co-pelletization of sewage sludge and biomass: The energy input and properties of pellets" Fuel Process. Technol.,vol.132, pp. 55-61, April 2015. 
[15] F. Fonseca, C. A. Luengo, J. A. Suárez and P. A. Beatón. "Wood briquette torrefaction". Energ Sust. Dev., vol. 9, pp. 19-22, March 2005.

[16] M. Katzer, S. Pirl, S. Esser, J. Kopietz, T. Rickmann, J. Behnisch and C. J. Klasen. "Residence time distribution in granulation drums, on the example of industrial carbon black". Chem. Eng. Technol., vol. 27, pp. 578-582, May 2004.

[17] T. H. Mwampamba, M. Owen and M. Pigaht. "Opportunities, challenges and way forward for the charcoal briquette industry in Sub-Saharan Africa”. Energ Sust. Dev., vol 17 pp. 158-170, April 2013.

[18] S. R. Teixeira, A. F. V. Pena and A. G. Migue. "Briquetting of charcoal from sugar-cane bagasse fly ash (scbfa) as an alternative fuel". Waste Manage., vol. 30, pp. 804-807, May 2010.

[19] A. Amaya, N. Medero, N. Tancredi, H. Silva, F. Sardella and C. Deiana. "Activated carbon briquettes from biomass materials". Bioresource Technol., vol. 98, pp. 1635-1641, May 2007.

[20] A. Amaya, J. Píriz, N. Tancredi and T. Cordero. "Activated carbon pellets from eucalyptus char and tar TG studies". J. Therm. Anal. Calorim., vol. 89, pp. 987-991, September 2007.

[21] N. Kaliyan and V. Morey. "Natural binders and solid bridge type binding mechanisms in briquettes and pellets made from corn stover and switchgrass". Bioresource Technol., vol. 101, pp. 1082-1090, February 2010.

[22] A. Kumar, N. Kumar, P. Baredar and A. Shukla. "A review on biomass energy resources, potential, conversion and policy in India”. Renew. Sust. Energy Reviews, vol. 45, pp. 530-539, February 2015.
[23] P. K. Halder, N. Paul and M.R.A. Beg. "Assessment of biomass energy resources and related technologies practice in Bangladesh". Renew. Sust. Energy Reviews, vol. 39, pp. 444-460, August 2014.

[24] O. A. Sotannde, A. O. Oluyege and G. B. Abah. "Physical and combustion properties of charcoal briquettes from neem wood residues”. Int. Agrophys., vol. 24, pp. 189-194, June 2010.

[25] DINACYT. "El enorme potencial de la madera uruguaya". Noticias DINACYT Nr. 253, March 2005.

[26] C. Faroppa, Evaluación de la disponibilidad de residuos o subproductos de biomasa a nivel nacional. Montevideo: Ministerio de Industria, Energía y Minería, Dirección Nacional de Energía y Tecnología Nuclear; ONUDI; Uruguay, 2010, pp. $5-18$.

[27] N. Tancredi, A. Cuña, J. P., Luizzi, M. Corengia, A. Sarachik, A Amaya."Obtention of charcoal from eucalyptus wood in a steel pilot scale kiln". In Charcoal: Chemical Properties, Production Methods and Applications. New York: Nova Science Inc. Publishers, pp 61-74, 2013.

[28] E. Purlis. "Browning development in bakery products - A review”. J. Food Eng., vol. 99, pp. 239-249, August 2010.

[29] K. J. Zhang and Y. Guo "Physical properties of solid fuel briquettes made from Caragana korshinskii”. Powder Technol., vol. 256, pp. 293-299, April 2014

[30] M. van Blijderveen, E. A. Bramer and G. Brem. "Modelling spontaneous ignition of wood, char and RDF in a lab-scale packed bed". Fuel, vol. 108, pp. 190-196, June 2013. 